\title{
e-Textile Embroidered Wearable Near-Field Communication RFID Antennas
}

DOI:

10.1049/iet-map.2018.5435

Document Version

Accepted author manuscript

Link to publication record in Manchester Research Explorer

\section{Citation for published version (APA):}

Jiang, Y., Xu, L., Pan, K., Leng, T., Li, Y., Danoon, L., \& Hu, Z. (2019). e-Textile Embroidered Wearable Near-Field Communication RFID Antennas. IET Microwaves, Antennas and Propagation. https://doi.org/10.1049/ietmap.2018.5435

\section{Published in:}

IET Microwaves, Antennas and Propagation

\section{Citing this paper}

Please note that where the full-text provided on Manchester Research Explorer is the Author Accepted Manuscript or Proof version this may differ from the final Published version. If citing, it is advised that you check and use the publisher's definitive version.

\section{General rights}

Copyright and moral rights for the publications made accessible in the Research Explorer are retained by the authors and/or other copyright owners and it is a condition of accessing publications that users recognise and abide by the legal requirements associated with these rights.

\section{Takedown policy}

If you believe that this document breaches copyright please refer to the University of Manchester's Takedown Procedures [http://man.ac.uk/04Y6Bo] or contact uml.scholarlycommunications@manchester.ac.uk providing relevant details, so we can investigate your claim.

\section{OPEN ACCESS}




\title{
e-Textile Embroidered Wearable Near-Field Communication RFID Antennas
}

\author{
Yutong Jiang ${ }^{1}$, Lulu Xu ${ }^{2}$, Kewen Pan ${ }^{1}$, Ting Leng ${ }^{1}, \mathrm{Yi} \mathrm{Li}^{2}$, Laith Danoon ${ }^{1}$ and Zhirun $\mathrm{Hu}^{1}$ \\ ${ }^{1}$ School of Electrical and Electronic Engineering, the University of Manchester, Oxford Road, Manchester, \\ United Kingdom. \\ ${ }^{2}$ School of Materials the University of Manchester, Oxford Road, Manchester, United Kingdom
}

\begin{abstract}
Wearable e-textile Near Field Communication (NFC) RFID antennas fully integrated with garments using embroidery techniques, which enables everyday clothing to become connective to wireless communication systems, is presented. The e-textile wearable antennas have been designed through full electromagnetic wave simulation based on the electrical properties of conductive treads and textile substrates at the High Frequency (HF) band, allocated for NFC wireless communications. The e-textile wearable NFC antenna performance under mechanical bending as well as human body effects have been experimentally studied and evaluated; the antennas can operate under significantly bending angle and body effects attributed to its broad operating bandwidth. This is highly desirable and distinguished to conventional NFC antennas; the proposed e-textile wearable NFC antennas can be placed almost any place on clothes and still capable to communicate at desired operating frequency of $13.56 \mathrm{MHz}$. The maximum read range of the e-textile wearable NFC tags are measured to be around $5.6 \mathrm{~cm}$, being compatible to typical commercially available metallic NFC tags. The e-textile wearable NFC tags can lead to numerous potential applications such as information exchange, personal security, health monitoring and loTs.
\end{abstract}

\section{Introduction}

In recent years, Near Field Communication (NFC) has become increasingly popular in commodity market and believed to be one of the technologies that would realize the ubiquitous connectivity between the virtual internet world and the physical world for internet of things (IoTs) applications. The main function of an NFC system is contactless communication between NFC tag and reader without the requirement of any external battery. The first development of NFC tags can be traced back to 1970 when it was called "Short-Range Radio-Telemetry for Electronic Identification Using Modulated Backscatter" [1]. Till this day, NFC technology has been applied in numerous fields such as, ID cards, debit/credit cards, itemized commodities and hotel room keys [2].

The operating frequency of an NFC antenna is typically set at $13.56 \mathrm{MHz}$. A passive NFC tag operates by the transmitted power from the reader [3]. Magnetic induction coupling is applied between the tag antenna and the reader antenna within a short distance to draw its necessary operating power for the IC chip on the tag from the reader's electromagnetic field. NFC antennas possess a working distance that is typically around a couple of $\mathrm{cm}$ to a few tens of $\mathrm{cm}$ and a data transfer rate around $424 \mathrm{kbits} / \mathrm{s}$ for which the maximum value is up to $848 \mathrm{kbits} / \mathrm{s}$ [4].

The application of NFC tags for wearable wireless communications has been challenging since existing antenna fabrication methods, including chemical etching and screen printing, are not particularly suitable for close-fitting wearables [5]. Recently, researchers have developed various types of textile antennas that realize off-body communications, such as patch antennas applied in protective clothing for firefighters and basic attachments for normal garments [6], [7]. Wearable UHF RFID antennas have also been developed and implemented on smart textiles for various applications, such as body centric sensing and apnea detection and the maximum read range is up to 16 meters for patch UHF RFID antenna circuits with microchip connections [8]-[11]. Very different from UHF RFIDs, NFC RFIDs have limited read range usually within a few centimetres, which are preferred in more personal applications that require high security levels. Moreover, NFC RFIDs can be read by NFC-enabled smartphones while the reading of UHF RFIDs requires specific receiving antenna with relatively large sizes [12].

Among existing NFC tag antenna research, [13] has analysed metal NFC circuit performance regarding to varies resonant frequencies and return loss presented with simulation results only, and [14] has mainly discussed how textile based NFC circuits measurements respond to different types of substrate material. In this paper, NFC RFID antennas integrated with garment using embroidery technology are proposed, designed, fabricated, measured and characterized. Different from previous research, our work focuses on design and performance of purely textile based NFC tags regarding to specific requirements for daily wearables, for instance, when an NFC tag is bent from body movements, the resonant frequency shifts away from $13.56 \mathrm{MHz}$, which could easily result in communication failure. To prevent this, the NFC structure in this work is designed to achieve an operating bandwidth that is considerably wider than commercial ones. In fabrication, conductive treads with fairly low resistivity are integrated seamlessly with skin-friendly textile material, such as cotton, which possesses the flexibility to be easily applied on everyday garments. Microchips are bonded on the NFC antennas, which contain the information to be accessed by an NFC reader wirelessly. The novel e-textile wearable NFC tags are expected to lead to numerous potential applications within the fields such as information exchange, personal security, health monitoring and IoTs [15]-[16].

This paper is structured as follows. Section II will discuss the design methodology of e-textile wearable NFC 
antennas, material selections and embroidery technique. In Section III, measurements of the fabricated NFC tags are presented together with their RF performance evaluation ( $\mathrm{S}$ parameters) under various degrees of bending. Furthermore, the wireless reading measurements of the NFC tags including the effects of bending and human body contact are provided. Section IV summarizes the key results and findings.

\section{Design methods and procedures}

\subsection{NFC Design and Simulation}

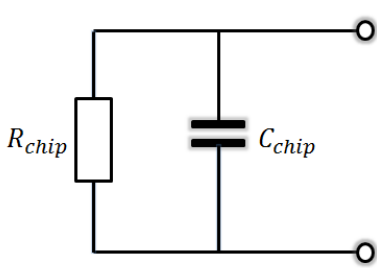

Microchip

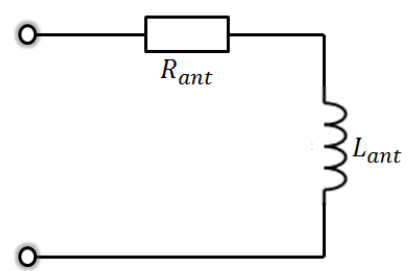

Antenna
Fig.1. Equivalent circuit model of an NFC-microchip matching network

For a passive NFC tag, the read range depends on the minimum transmitted power needed to operate the tag circuitry. Therefore, the main challenges in the design process are (a) to minimize the power dissipated by the antenna and (b) to maximize the conversion efficiency between the electromagnetic power from the reader and the DC power consumed by the tag [3].

Fig. 1 presents a simplified equivalent circuit for the microchip and antenna, where the antenna is designed to conjugately match the microchip. The antenna inductance $\boldsymbol{L}_{\boldsymbol{a n t}}$ which can be derived from (1) [17],

$$
L_{\text {ant }}=\frac{1}{\left(2 \pi f_{r}\right)^{2} C_{\text {chip }}}
$$

where $\boldsymbol{f}_{\boldsymbol{r}}$ stands for the circuit resonant frequency and $\boldsymbol{C}_{\text {chip }}$ stands for the chip capacitance

Commercially available metallic NFC tags are usually designed with narrow bandwidth and $\mathrm{Q}$ factor around 30-40 in order to achieve high transmitting efficiency [18]. However, textile based NFC tags especially require relatively wide operating bandwidth to be able to tolerate clothing shape change and human body effects. The proposed NFC structure is designed and optimized to meet this requirement.

The NFC antennas in this work have been designed in a shape of rectangular spiral coil. The antenna dimensions are optimized with the antenna inductance according to (2) [17], based on which the preliminary layout of the NFC antenna is built for full wave simulation.

$$
L_{\text {ant }}=K_{1} \mu_{0} N^{2} \frac{d}{1+K_{2} p}
$$

where $\boldsymbol{d}$ is the coil diameter which is the mean value of the outer and inner diameters of the coil $\left(\boldsymbol{d}_{\text {out }}\right.$ and $\left.\boldsymbol{d}_{\text {in }}\right)$; Note: for a square shaped coil, $\boldsymbol{d}_{\text {out }}$ and $\boldsymbol{d}_{\text {in }}$ respectively represent the outer and inner lengths of the edges which are highlighted in Fig. 2. $\boldsymbol{N}$ is the number of turns; $\boldsymbol{K}_{\boldsymbol{l}}$ and $\boldsymbol{K}_{2}$ are parameters that depend on the layout, which are respectively 2.34 and 2.75 for square line inductors [12]; $\boldsymbol{\mu}_{\boldsymbol{0}}$ is the free space permeability and $p=\left(d_{\text {out }}-d_{\text {in }}\right) /\left(d_{\text {out }}+d_{\text {in }}\right)$.

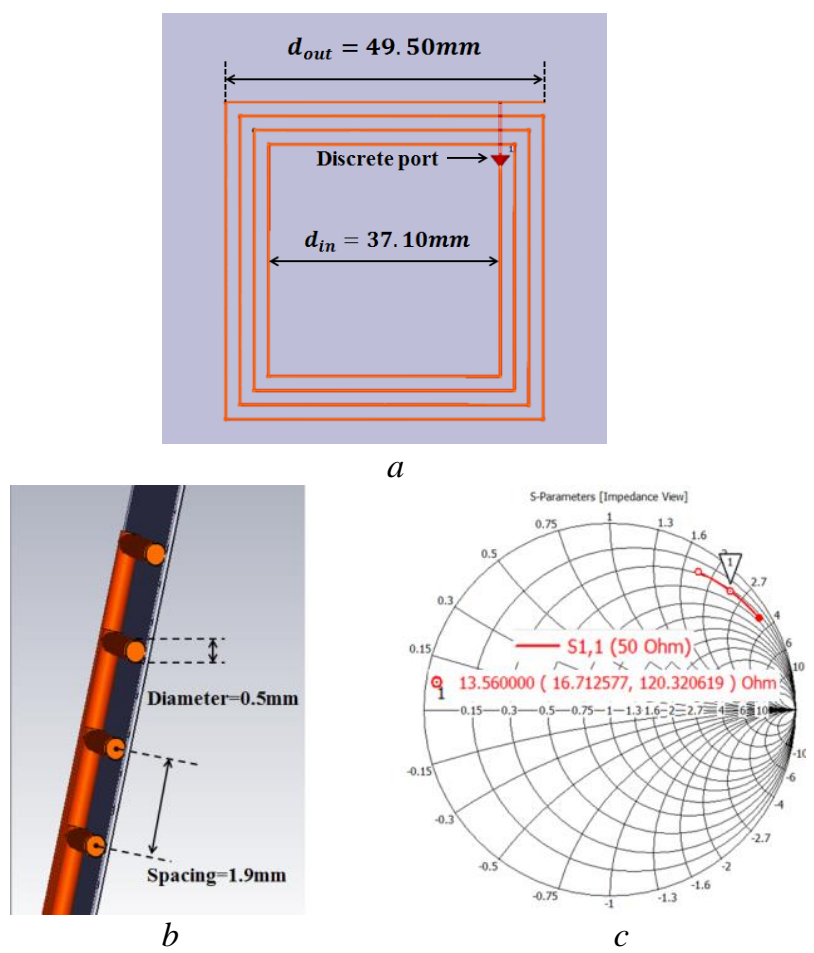

Fig. 2. CST model of designed NFC RFID antenna and simulated results

(a) Model front view, (b) Cross-section cutting plane, (c) Simulated reflection coefficient $\left(\mathrm{S}_{11}\right)$ from the CST model

Fig. 2(a) and (b) present the NFC antenna layout created with CST Microwave Studio [19]. The antenna is fed by a discrete port that connects both ends of the NFC coil. The cross section of the thread is assumed to be circle with radius of $0.25 \mathrm{~mm}$. The choice of threads and yarns for these NFC RFID antennas is a trade-off between their electrical and mechanical properties. In other words, they are selected to be not only conductive but also structurally stable under possible bending [20]. In order to meet these requirements, threads used to construct NFC antennas are chosen as polyamide threads coated with silver. Although metal wire threads have also been considered in the design process due to their relatively low resistivity, their toughness and electrical stability are rather low and less suitable for textile circuits. The thread used in this work has a resistivity of $17.2 \Omega / \mathrm{m}$, which is an order higher than aluminium used for commercial metallic NFC antennas. Cotton $(\mathrm{Er}=2.31)$ has been chosen as substrate material due to its comfort level to human skin. NXP SL2S2102FTB microchip has been chosen in this work. The chip input capacitance is 97 $\mathrm{pF}$ at $13.56 \mathrm{MHz}$

Fig. 2(c) illustrates simulated reflection coefficient (S11) of the optimized NFC antenna in the Smith chart. The NFC antenna model has impedance of $16.71+\mathrm{j} 120.32 \Omega$ at $13.56 \mathrm{MHz}$, which indicates an antenna inductance of $1.41 \mu \mathrm{H}$. The imaginary part conjugately matches the

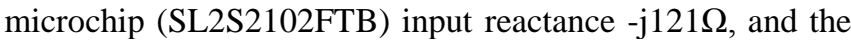
chip resistance is large enough to be considered as an open circuit and therefore to be ignored in the connection with tag coil [21]. 


\subsection{Fabrication}

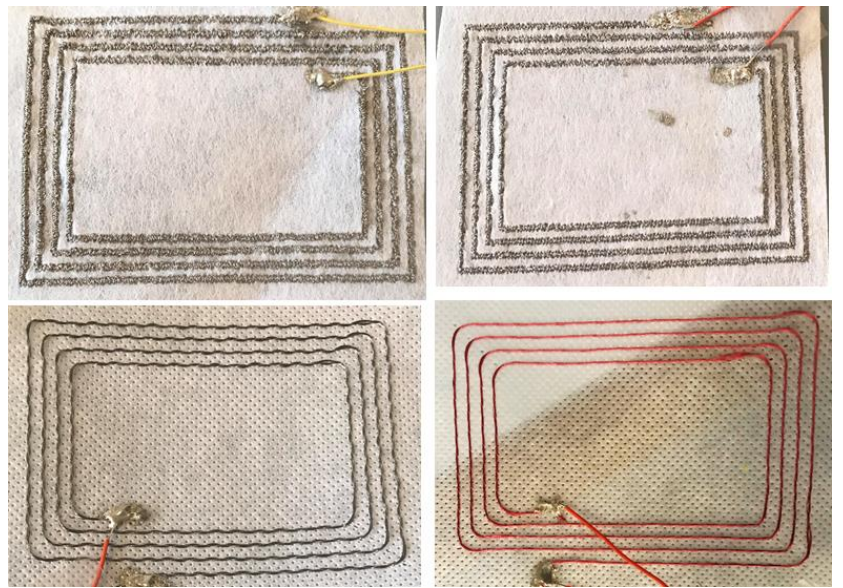

Fig. 3. Selected NFC antenna samples

Thirty NFC antenna prototypes embroidered on cotton substrate, made with conductive yarns coated with several types of metals, including silver, stainless steel and aluminium, have been designed and fabricated on cotton. Four samples of these circuits are shown in Fig. 3. Among all the coating materials, silver and stainless steel are believed to be the best choices for such conductive yarns to apply on wearables [22], [23]. Because of the high inertness of these two types of metal, they would not be much affected by sweat or moisture from the user. Moreover, silver and stainless steel have a high resistance against water and low concentrated acid so that the textile circuit would be applicable to dry cleaning and even mild water cleaning.

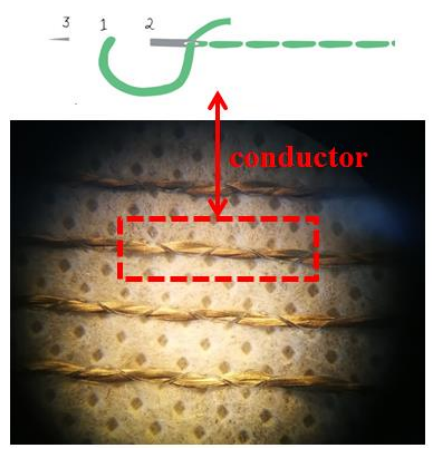

$a$

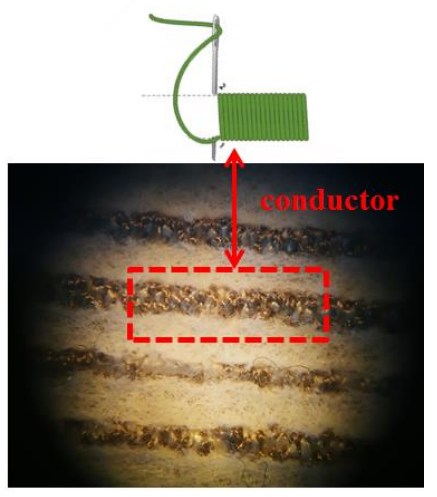

b
Fig. 4. Stainless steel coated NFC antennas observed under a microscope corresponding to two different fabrication techniques:

(a) Back stitch technique, (b) Satin stitch technique

Fig. 4 illustrates two embroidery techniques, back stitch and satin stitch, in fabricating NFC antennas respectively. Both antennas were constructed using stainless steel coated nylon threads. From the perspective of the stability of the structure, satin stitch is better than back stitch since it is more difficult to be snapped or ripped off. However, due to the fact that the satin stitch requires much longer threads for the same antenna size, the DC resistance of the antenna in Fig. 4(b) is measured as $70 \Omega$, which is much higher than the one in Fig. 4(a) that is $11.6 \Omega$. For this very reason, back stitch is used in this work.

\section{Results and discussion}

\subsection{DC characteristics}

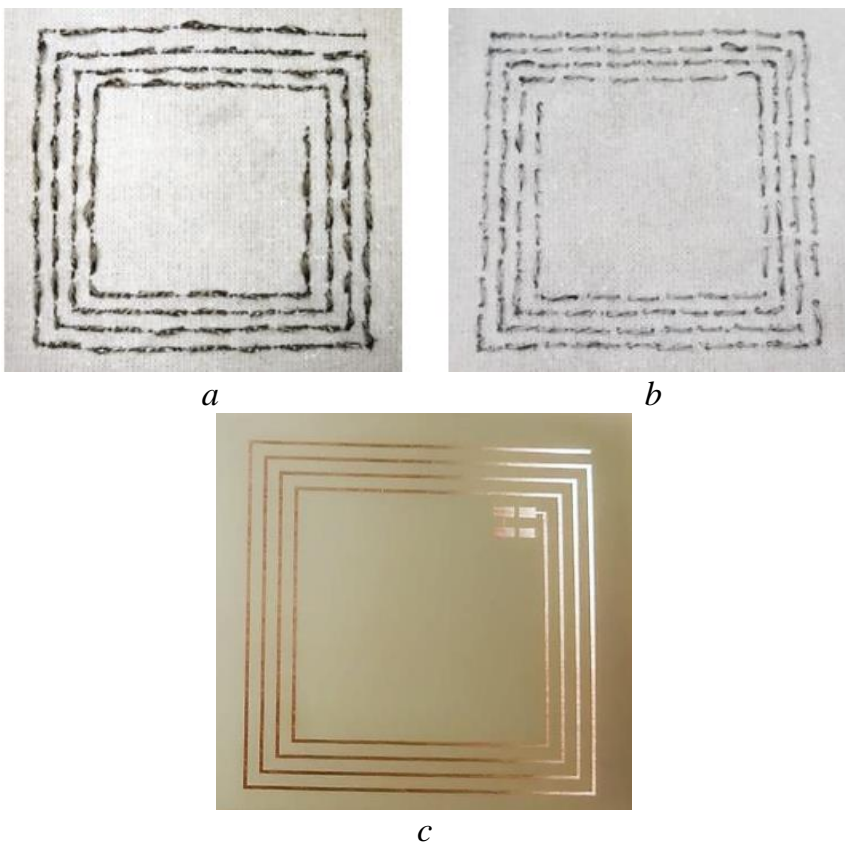

Fig. 5. NFC antenna prototypes

(a) Silver coated conductive threads embroidered with cotton, (b) Stainless steel coated conductive threads embroidered with cotton, (c) Copper on PCB

In Fig. 5, three NFC RFID antennas with the same structure are presented, where Fig. 5(a) is the proposed circuit and Fig. 5(b) and (c) are fabricated for the purpose of performance comparison. The antenna dimensions are listed in Table 1. Fig. 5(a) and (b) show antenna coils made with silver coated nylon conductive threads with $0.5 \mathrm{~mm}$ thickness (Arduino Flux Workshop) and stainless steel coated conductive treads with $0.3 \mathrm{~mm}$ thickness (BEKAERT) by back stitch embroidery technique. The DC resistance of the antenna is measured as $9.9 \Omega$ and $21.6 \Omega$ respectively. A copper NFC tag with on FR4 substrate $(\mathrm{Er}=4.7)$ with a line width of $0.5 \mathrm{~mm}$ and a thickness of $17.5 \mu \mathrm{m}$ is presented in Fig. 5(c) as copper is one of the most common material in commercial NFC manufacture, the DC resistance of which is only $2.2 \Omega$.

Table 1 NFC antenna parameters

\begin{tabular}{llll}
\hline $\begin{array}{l}\text { Length } \\
(\mathrm{mm})\end{array}$ & $\begin{array}{l}\text { Width } \\
(\mathrm{mm})\end{array}$ & $\begin{array}{l}\text { Spacing } \\
\text { between turns } \\
(\mathrm{mm})\end{array}$ & $\begin{array}{l}\text { Number of } \\
\text { turns }\end{array}$ \\
\hline 49.5 & 49.5 & 1.9 & 4
\end{tabular}

The antenna is designed to be matched up with an NXP microchip SL2S2102FTB which can be regarded as purely capacitive. Referring to Fig. 1, only the imaginary parts between the microchip and antenna can be matched conjugately as the coil antenna can't be lossless. To realize the best power transmitting efficiency the microchip series resistance (approximately zero) and antenna resistance need to be as close as possible [24]. Therefore, silver coated conductive threads are preferred rather than those with stainless steel coatings due to a lower resistivity. 


\subsection{Bandwidth}

In order to verify the resonant frequency and bandwidth of the NFC tag antennas, S-parameters of the antenna were measured using Keysight Fieldfox VNA N9918A.

Fig. 6(a) shows the S11 of the silver coated textile antenna coil in the Smith chart, the antenna has measured impedance of $13.5+\mathrm{j} 119.5 \Omega$ at $13.56 \mathrm{MHz}$, which is fairly close to the designed value $(16.7+\mathrm{j} 120.3 \Omega)$. The coil inductance calculated from this measurement is $1.4 \mu \mathrm{H}$.

The quality factor of the antenna can be calculated from the measured resistance and inductance using (3) [25],

$$
Q=\frac{2 \pi f_{r} L_{a n t}}{R}
$$

where $\boldsymbol{f}_{\boldsymbol{r}}$ is the antenna resonant frequency and $\boldsymbol{L}_{\boldsymbol{a n t}}$ and $\boldsymbol{R}$ are the coil inductance and resistance respectively. The $\mathrm{Q}$ factor of the proposed textile NFC tag is 8.85 .

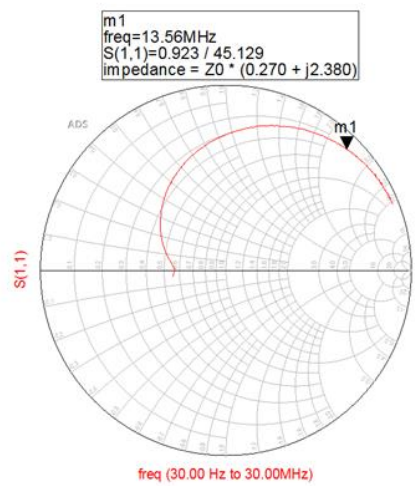

$a$

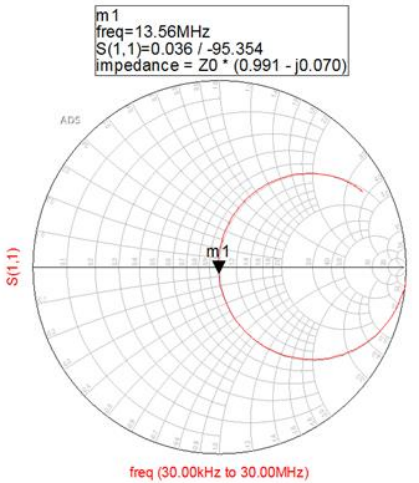

b
Fig. 6. Measured reflection coefficient $S_{11}$ in Smith Chart format:

(a) Antenna coil measurements, (b) Antenna connected with matching circuit

In order to test the tag performance at the operating frequency, a matching circuit consisted with a resistor $(36 \Omega)$ and a capacitor $(97 \mathrm{pF})$ is connected in series with the antenna coil. The capacitor value is chosen as the input capacitance of the microchip so that the imaginary part is matched to zero, and the purpose of the series resistor is to match the circuit impedance with the VNA input impedance $(50 \Omega)$ in order to minimize reflected power at the resonant point. The circuit impedance after matching is presented in Fig. 6(b), where the admittance is almost entirely cancelled out and the resistance is matched to approximated $50 \Omega$.

Fig. 7 depicts the measured $S_{11}$ magnitude of the three NFC antennas shown in Fig. 5. The detailed comparison results are listed in Table 2. All three antennas resonate around $13.56 \mathrm{MHz}$ as designed with return loss of $32.52 \mathrm{~dB},-32.03 \mathrm{~dB}$ and $-38.09 \mathrm{~dB}$, respectively. The $10 \mathrm{~dB}$ bandwidth results of the textile antennas coated with silver $(3.787 \mathrm{MHz})$ and stainless steel $(3.794 \mathrm{MHz})$ are slightly wider than the one of copper antenna $(3.61 \mathrm{MHz})$, which is also considerably wider than that of commercial NFC tag antennas [26]. The wide bandwidth is a critical parameter for wearable applications as the resonant frequency of the antenna shifts when the garment bends. For a narrow band antenna, the shift of the resonance frequency will cause the tag unreadable by NFC readers.

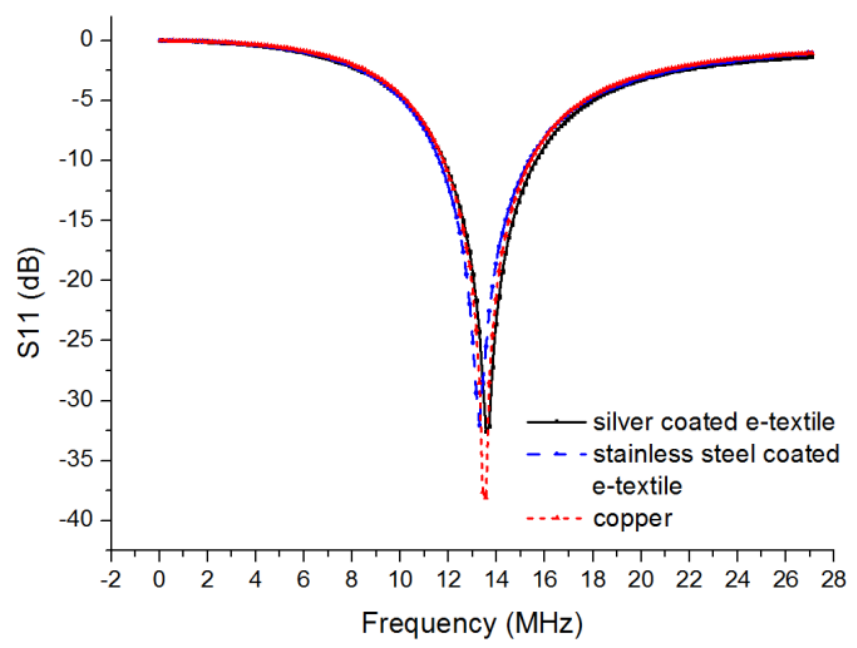

Fig. 7. $S_{11}$ results of $N F C$ circuits made of e-textile and copper in magnitude $(d B)$ against frequency

In Table 2, the $\mathrm{Q}$ factor of copper NFC circuit is considerably higher than the ones made with metal coated conductive threads since the power transmitting efficiency is directly related to the antenna resistance. Considering a trade-off between the working efficiency and operating bandwidth required for textile integrated circuits, the proposed silver coated e-textile based NFC antenna is fairly applicable.

Table 2 Experimental result comparison between NFC tags manufactured with e-textile and copper

\begin{tabular}{llll}
\hline Material & $\begin{array}{l}\text { Silver } \\
\text { coated }\end{array}$ & $\begin{array}{l}\text { Stainless } \\
\text { steel coated }\end{array}$ & Copper \\
\hline $\begin{array}{l}\text { DC resistance } \\
(\Omega)\end{array}$ & 9.9 & 21.6 & 2.2 \\
\hline $\begin{array}{l}\text { Network } \\
\text { impedance at }\end{array}$ & $13.5+$ & $26.2+$ & $2.5+$ \\
$\begin{array}{l}13.56 \mathrm{MHz}(\Omega) \\
\mathrm{Q} \text { factor }\end{array}$ & $\mathrm{j} 119.5$ & $\mathrm{j} 124.5$ & $\mathrm{j} 119.2$ \\
\hline $\begin{array}{l}\text { Maximum } \\
\text { transmitted } \\
\text { energy }(\mathrm{dB})\end{array}$ & 32.52 & 4.75 & 47.7 \\
\hline $\begin{array}{l}\text { 10dB } \\
\text { bandwidth } \\
(\mathrm{MHz})\end{array}$ & 3.787 & 32.03 & 38.09 \\
\hline
\end{tabular}

\subsection{Bending test}

To integrate e-textile NFC RFID antennas into closefitting garments, it is essential to ensure it has stable electrical properties, such as operating efficiency and read range, when the antenna is under natural human body movements. Since the antenna is applied to a cotton substrate which can be easily bent out of shape, natural bending seems to be the factor that would most likely affect the antenna operation. Therefore, it is necessary to determine how the antenna performance would change with different bending. 


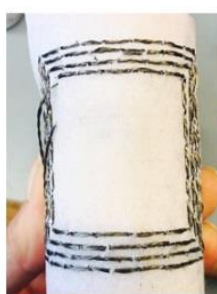

a

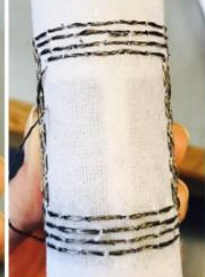

$b$

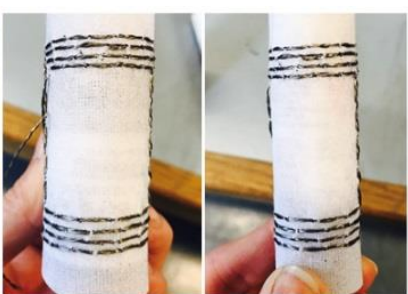

$c$ $d$
Fig. 8. Antenna bent around four cylinders with decreasing diameters of:

(a) $35 \mathrm{~mm}$, (b) $28 \mathrm{~mm}$, (c) $23 \mathrm{~mm}$, (d) $17 \mathrm{~mm}$

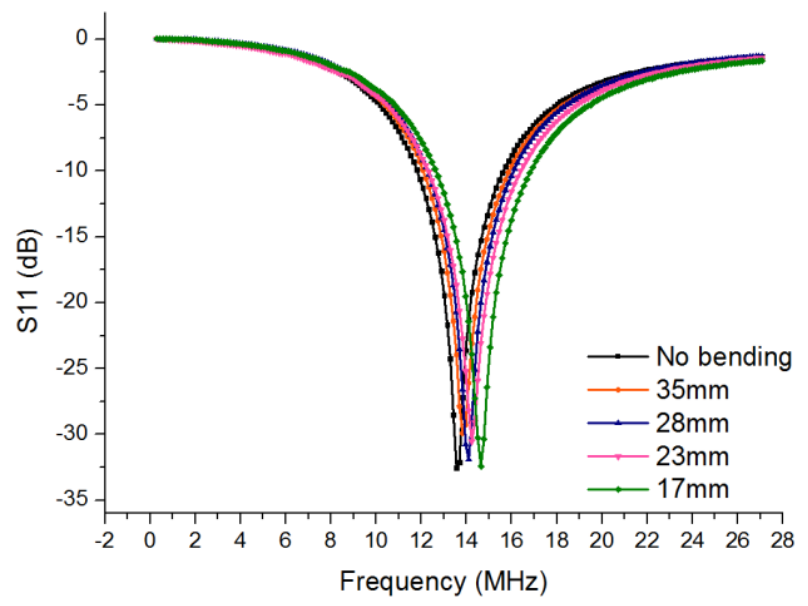

Fig. 9. Measured $S_{11}$ magnitudes for 4 different bending cases shown in Fig. 8 and without bending

Fig. 8 illustrates bending tests of the NFC antenna using $U$ bend method [27] where four plastic cylinders with different diameters are applied for the NFC antenna to be bent around. The measured S11 magnitude and impedance with and without bending are shown in Fig. 9 and Table 3, respectively.

As presented in Fig. 9, the resonance frequency and operational bandwidth of the NFC antenna change slightly as the bending increases. However, due to the broad bandwidth of the antenna, the shift of resonant frequency would not affect the RFID reading as long as $13.56 \mathrm{MHz}$ still falls within the $10 \mathrm{~dB}$ bandwidth.

Table 3 Results for bending tests

\begin{tabular}{llllll}
\hline $\begin{array}{l}\text { Bending } \\
\text { diameter } \\
/ \mathrm{mm}\end{array}$ & N/A & 35 & 28 & 23 & 17 \\
\hline & & & & & \\
$\mathrm{f}_{\mathrm{c}} / \mathrm{MHZ}$ & 13.56 & 13.82 & 14.10 & 14.23 & 14.64 \\
\hline Return & -32.52 & -29.91 & -31.1 & -30.54 & -32.42 \\
loss/dB & & & & & \\
\hline $\mathrm{Z}\left(\mathrm{f}_{\mathrm{c}}\right) / \Omega$ & $49.6-$ & $51.9-$ & $50.5-$ & $50.9-$ & $50.4-$ \\
& $\mathrm{j} 3.5$ & $\mathrm{j} 8.9$ & $\mathrm{j} 11.8$ & $\mathrm{j} 14.6$ & $\mathrm{j} 20.2$ \\
\hline
\end{tabular}

In Table $3, \boldsymbol{Z}\left(\boldsymbol{f}_{\boldsymbol{c}}\right)$ represents the matched antenna impedance at each central frequency for different bending. The imaginary part of the antenna impedance decreases as the bending increases, which indicates gradual decrements of the antenna inductance. This is due to the fact that when the antenna is no longer planar but bent around the cylinder, the current flowing in the opposing sides of the antenna is drawn closer to each other, thus the electromagnetic field exists on both sides of the circuit tend to introduce extra electrical coupling that cancels out the inductance of the antenna. Consequently, the NFC resonance frequency goes up as the antenna inductance decreases.

\subsection{Power transmission and Wireless reading}

After the NFC antenna is connected with a microchip, the contactless antenna verification method described in [17] is performed to determine the NFC antenna power transmission pattern during wireless measurements as presented in Fig. 10(a).

From the measurements shown in Fig. 10(b), the detected voltage levels with an oscilloscope are higher than the source voltage $(0.25 \mathrm{~V})$, which means the magnetic field produced by the generator coil induces a current flow in the NFC tag, and the magnetic field generated from this current is captured by the oscilloscope coil. At tag resonant frequency, the current flowing into the tag antenna is maximized. As a result, the proposed NFC antenna is able to achieve the maximum transmitted power at $13.6 \mathrm{MHz}$, showing the antenna is well tuned.

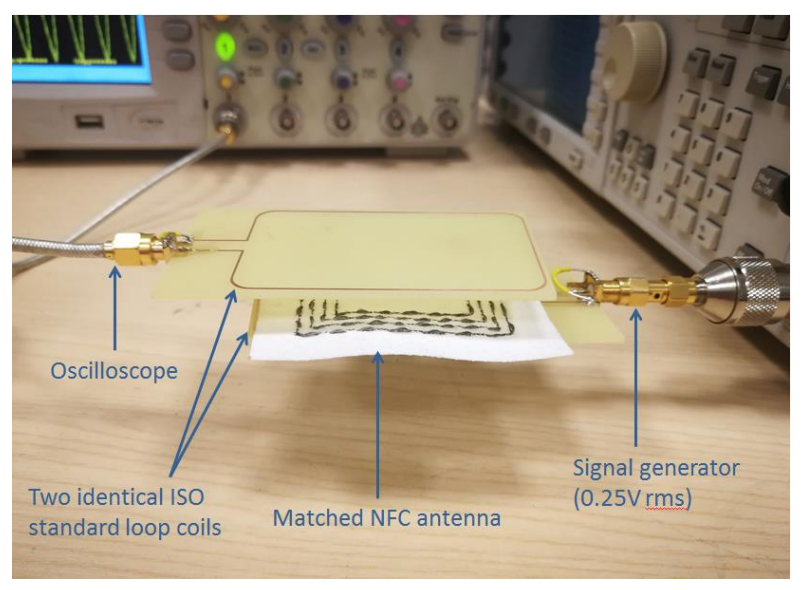

$a$

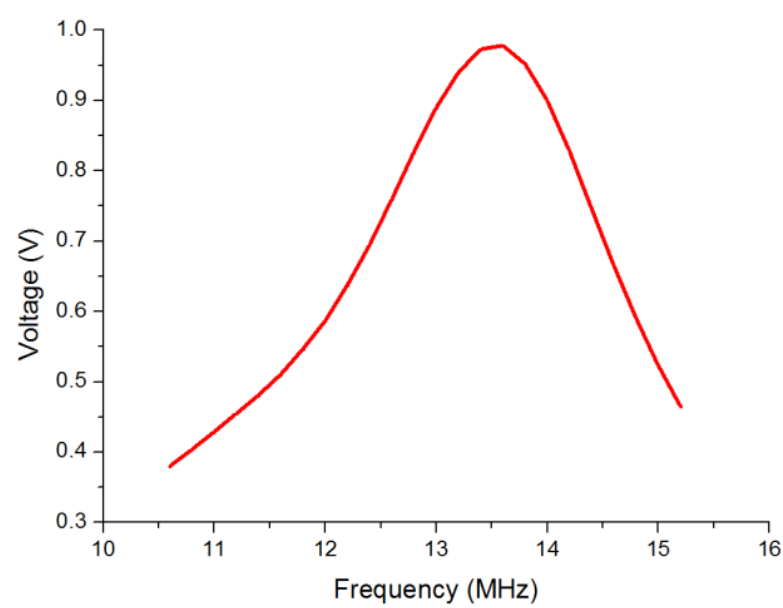

$b$

Fig. 10. Contactless antenna verification

(a) Measurement set up, (b) Detected voltage level vs frequency

In order to measure the NFC tag read range, a microchip (NXP SL2S2102FTB) has been connected to the NFC antenna as shown in Fig. 11(a). 
A USB-connected Texas Instruments reader, (TRF7970A) is used for the read range measurement. The experimental set up for tag reading is presented in Fig. 11(b), where the reader is held horizontally above the tag with a laboratory stand and the distance between is measured with an electrical vernier caliper. It is crucial that no metal surface is near the tag or the reader, otherwise the read distance would be affected. Once an NFC tag is held within a certain range of the reader, the red LED on the reader goes on as shown in Fig. 11(c) and (d), meaning the RFID data has been received by the reader.

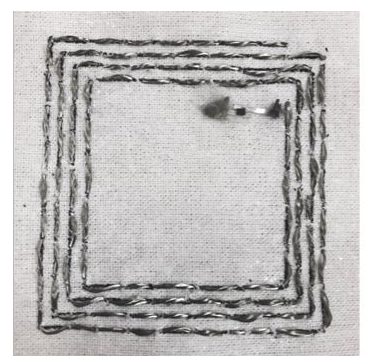

$a$

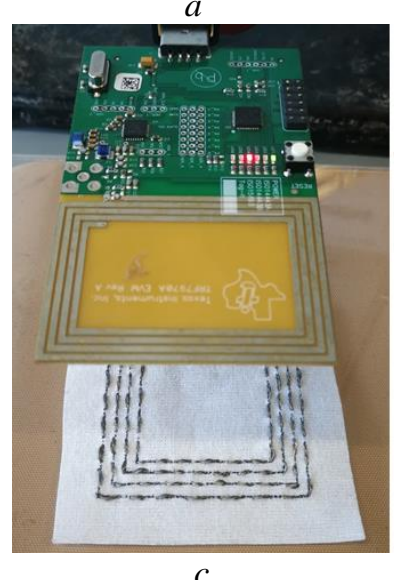

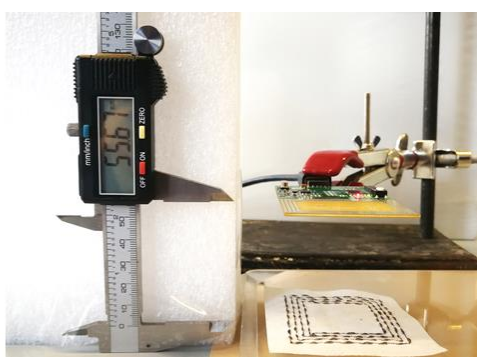

$b$

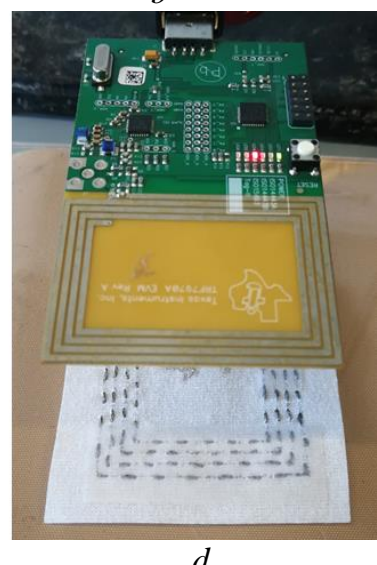

$d$
Fig. 11. Read distance measurements

(a) Fabricated e-textile wearable NFC RFID tag, (b) Tag reading experimental set up, (c) NFC tag detected by the RFID reader (facing forward), (d) NFC tag detected by the RFID reader (facing backward)

Both forward and backward facing directions were tested in the measurements, between which hardly any difference has been observed. The best read range of the NFC RFID tag is $5.57 \mathrm{~cm}$. Comparing to the read distance of a commercial aluminium NFC tag (ST25TA64K) tested with the same reader which is $8.17 \mathrm{~cm}$; such results are satisfying for an NFC tag that aims for short range reading.

A simple bending test has also been applied in order to observe the read range limits of the tag, where a V-bend method has been carried out [27] as shown in Fig. 12(a) and (b). The bending angles are set up with an electrical angle meter and maintained with scotch tapes and plastic tweezers during measurements. The results are presented in Fig. 12(c), showing how the read range is affected by increasing degree of bending.

As the antenna working frequency shifts further from its original point with increasing degrees of bending, the reflected power from the NFC tag gradually decreases. Consequently, the read range of the tag is shortened since there is less magnetic flux going through the antenna coil. Nonetheless, due to the wide bandwidth of the antenna, the
NFC tag is able to be read within $0.5 \mathrm{~cm}$ even though the tag is almost completely folded ( $180^{\circ}$ bending angle).
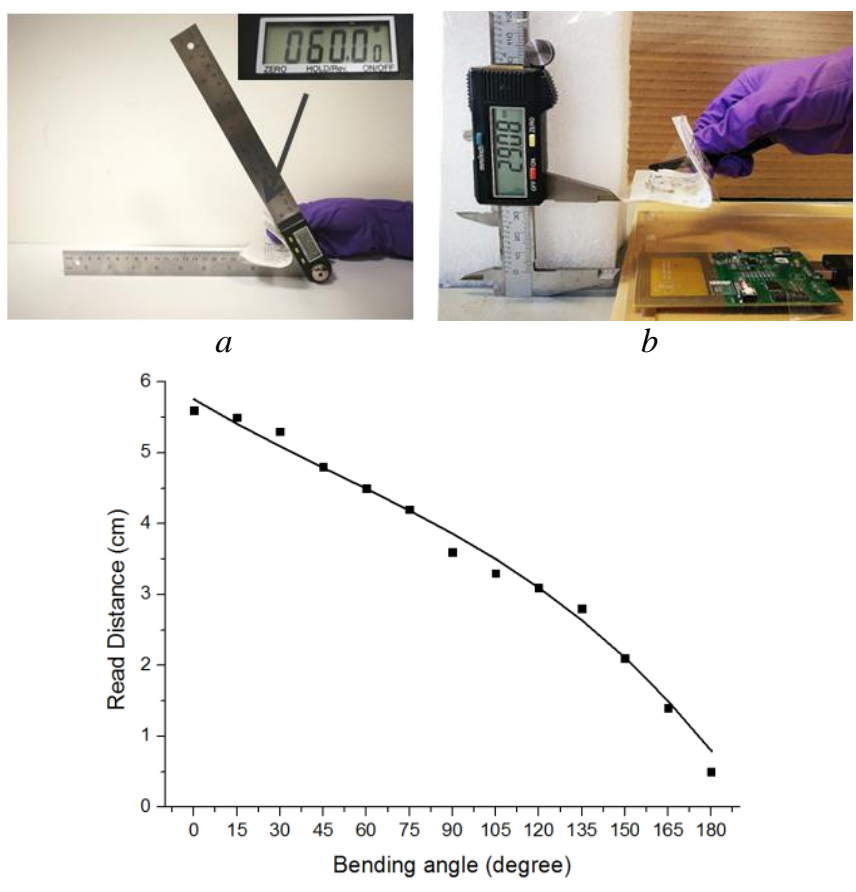

c

Fig. 12. Wirless bending test

(a) 120 degree V-bend set up, (b) Tag read with 120 degree bend angle, (c) NFC tag read range decreases with increasing degree of bending

\subsection{Effects of human body}

Table 4 NFC read range with different levels of skin contact

\begin{tabular}{ll}
\hline Condition & Read range $(\mathrm{cm})$ \\
\hline $\begin{array}{l}\text { Direct skin contact } \\
\text { Vicinity of skin without }\end{array}$ & 5.3 \\
touching $(1 \mathrm{~mm})$ & 5.5 \\
\hline $\begin{array}{l}\text { A thin cotton layer }(0.5 \mathrm{~mm} \\
\text { thickness) between skin } \\
\text { and tag }\end{array}$ & 5.5 \\
\hline Without skin contact & 5.6 \\
\hline
\end{tabular}

In order to ensure the e-textile wearable NFC RFID tag is fully functional in daily use, it is necessary to take measurements with human skin contact. In existing research, [28] has presented that how vicinity of skin affects the performance of wearable patch antennas. Since the NFC coil in this paper is seamlessly integrated with very light substrate, direct skin contact can easily occur.

Among all conditions listed in Table 4, the tag is mostly reduced by direct skin contact. This is due to the fact that transmitted EM energy is partially absorbed by body tissue layers, which leads to a slight reduction in the tag current [29].

\section{Conclusion}

This paper has presented the design and fabrication process of novel e-textile wearable NFC antennas which are fully integrated with garment, enabling truly ubiquitous 
wireless connectivity to everyday clothing. The NFC tags perform well under bending and human body effects. The 10 $\mathrm{dB}$ bandwidth of the fabricated NFC antenna is $3.787 \mathrm{MHz}$ and the quality factor is 8.85 . The broad operation bandwidth of the e-textile NFC RFID tags proposed in this work is highly desirable for smart textile due to its flexibility towards bending and can potentially lead to numerous applications, such as personal security, health and wellbeing monitoring, big data and IoTs.

\section{References}

[1] Landt, J. (2005). The history of RFID. IEEE Potentials, 24(4), pp.8-11.

[2] Coskun, V., Ok, K. and Ozdenizci, B. (2011). Near Field Communication (NFC). 1st ed. Somerset: Wiley.

[3] Roselli, L. (2014). Green RFID systems. 1st ed. Cambridge, United Kingdom: Cambridge University Press, p.8.

[4] Curran, K., Millar, A. and Mc Garvey, C. (2012). Near Field Communication. International Journal of Electrical and Computer Engineering (IJECE), 2(3).

[5] Choi, E., Park, J., Kim, B. and Lee, D. (2015). Fabrication of electrodes and near-field communication tags based on screen printing of silver seed patterns and copper electroless plating. International Journal of Precision Engineering and Manufacturing, 16(10), pp.2199-2204.

[6] Hertleer, C., Rogier, H., Vallozzi, L. and Van Langenhove, L. (2009). A Textile Antenna for Off-Body Communication Integrated Into Protective Clothing for Firefighters. IEEE Transactions on Antennas and Propagation, 57(4), pp.919-925.

[7] Chen, S., Kaufmann, T., Ranasinghe, D. and Fumeaux, C. (2016). A Modular Textile Antenna Design Using Snapon Buttons for Wearable Applications. IEEE Transactions on Antennas and Propagation, 64(3), pp.894-903.

[8] K. Koski, L. Sydänheimo, Y. Rahmat-Samii and L. Ukkonen, "Fundamental Characteristics of Electro-Textiles in Wearable UHF RFID Patch Antennas for Body-Centric Sensing Systems," in IEEE Transactions on Antennas and Propagation, vol. 62, no. 12, pp. 6454-6462, Dec. 2014.

[9] W. M. Mongan, I. Rasheed, K. Ved, A. Levitt, E. Anday, K. Dandekar, G. Dion, T. Kurzweg, and A. Fontecchio, "Real-time detection of apnea via signal processing of timeseries properties of RFID-based smart garments," in 2016 IEEE Signal Processing in Medicine and Biology Symposium (SPMB), 2016, pp. 1-6.

[10] Virkki, J., Wei, Z., Liu, A., Ukkonen, L. and Björninen, T. (2017). Wearable Passive E-Textile UHF RFID Tag Based on a Slotted Patch Antenna with Sewn Ground and Microchip Interconnections. International Journal of Antennas and Propagation, 2017, pp.1-8.
[11] Ginestet, G., Brechet, N., Torres, J., Moradi, E., Ukkonen, L., Bjorninen, T. and Virkki, J. (2017). Embroidered Antenna-Microchip Interconnections and Contour Antennas in Passive UHF RFID Textile Tags. IEEE Antennas and Wireless Propagation Letters, 16, pp.12051208.

[12] Nikitin, P. and Rao, K. (2006). Theory and measurement of backscattering from RFID tags. IEEE Antennas and Propagation Magazine, 48(6), pp.212-218.

[13] Iqbal, R. and Saeed, M. (2014). Wearable Near Field Communication Ring Antenna for Mobile Communication. International Conference on Open Source Systems and Technologies.

[14] Del-Rio-Ruiz, R. and Lopez-Garde, J. (2017). Design and Performance Analysis of a Purely Textile Spiral Antenna for On-Body NFC Applications. IEEE MTT-S International Microwave Workshop Series on Advanced Materials and Processes.

[15]Shaikh, F., Zeadally, S. and Exposito, E. (2017). Enabling Technologies for Green Internet of Things. IEEE Systems Journal, 11(2), pp.983-994.

[16] Atzori, L., Iera, A. and Morabito, G. (2010). The Internet of Things: A survey. Computer Networks, 54(15), pp. 2787-2805.

[17] How to design a $13.56 \mathrm{MHz}$ customized tag antenna. (2009). AN2866 Application note. [online] Available at: http://www.ebvnews.ru/doc/AN15284.pdf [Accessed 10 Mar. 2017].

[18] RF430CL330H Practical Antenna Design Guide. (2014). TEXAS INSTRUMRNTS, (SLOA197).

[19] Cst.com. (2017). CST MICROWAVE STUDIO® - 3D EM Simulation Software. [online] Available at: https://www.cst.com/products/cstmws [Accessed 26 Nov. 2017].

[20] Post, E., Orth, M., Russo, P. and Gershenfeld, N. (2000). E-broidery: Design and fabrication of textile-based computing. IBM Systems Journal, 39(3.4), pp.840-860.

[21] Farnell.com. (2017). [online] Available at: http://www.farnell.com/datasheets/1683422.pdf?_ga=2.6110 7945.41218670.1493817437-1811059628.1491485357 [Accessed 26 Nov. 2017].

[22] Atwa, Y., Maheshwari, N. and Goldthorpe, I. (2015). Silver nanowire coated threads for electrically conductive textiles. J. Mater. Chem. C, 3(16), pp.3908-3912.

[23] JOSEPH, S., MCCLURE, J., CHIANELLI, R., PICH, P. and SEBASTIAN, P. (2005). Conducting polymer-coated stainless steel bipolar plates for proton exchange membrane fuel cells (PEMFC). International Journal of Hydrogen Energy, 30(12), pp.1339-1344. 
[24] Rahola, J. (2008). Power Waves and Conjugate

Matching. IEEE Transactions on Circuits and Systems II:

Express Briefs, 55(1), pp.92-96.

[25] Measurement and tuning of a NFC and Reader IC antenna with a MiniVNA. (2014). AN11535, (291991).

[26] Lee, Y. (1998). RFID coil design. Microchip Technol. Inc. Appl. Note.

[27] ASTM E290-14 Standard Test Methods for Bend Testing of Material for Ductility, ASTM International, West Conshohocken, PA, 2014, https://doi.org/10.1520/E0290-14

[28] P. Salonen, Y. Rahmnat-Sarnii, and M. Kivikoski (2004), "Wearable Antennas in the Vicinity of Human Body," IEEE International Symposium on Antennas and Propagation Digest, 1, June 20-25, 2004, pp. 467-470.

[29] Klemm, M. and Troester, G. (2006). EM ENERGY ABSORPTION IN THE HUMAN BODY TISSUES DUE TO UWB ANTENNAS. Progress In Electromagnetics Research, 62, pp.261-280. 